\title{
VULNERABILIDADE DOS PÚBLICOS FRENTE \\ A PRÁTICAS ABUSIVAS DE COMUNICAÇÃo EMPREGADAS POR ORGANIZAÇÕES: \\ LIMITAÇÕES PARA O MONITORAMENTO CIVIL
}

\author{
Marcio Simeone Henriques \& Daniel Reis Silva \\ simeone@fafich.ufmg.br; daniel.rs@hotmail.com.br \\ Faculdade de Filosofia e Ciências Humanas - Universidade Federal de Minas \\ Gerais Belo Horizonte, MG - CEP 31270-901 - Brasil
}

\begin{abstract}
Resumo
O presente artigo reflete acerca da vigilância civil sobre práticas de comunicação abusivas empregadas por organizações privadas, abordando como tais práticas, voltadas para uma tentativa de corromper a opinião pública, criam uma categoria difusa cujo monitoramento é permeado por entraves e dificuldades. Em seguida explora especificamente a prática do astroturfing, entendida como uma manifestação de um público simulado, refletindo sobre como suas lógicas configuram uma prática ambígua e indeterminada.
\end{abstract}

Palavras-chave

Comunicação nas organizações; práticas de comunicação abusivas; vigilância civil; astroturfing; monitoramento da comunicação

\section{INTRODUÇÃo}

Nos últimos anos, o surgimento e a atuação de iniciativas civis voltadas para a vigilância de práticas abusivas de comunicação empregadas por organizações privadas reconfiguraram elementos da multifacetada relação organizações-sociedade, alçando os próprios públicos a uma posição central na defesa de seus interesses. Em diversos países do mundo, portais na internet e blogs' começam a tomar a forma de uma rede de radares de vigilância voltados especificamente para o monitoramento de práticas abusivas de comunicação das organizações, produzindo um grande número de denúncias envolvendo algumas das maiores corporações da atualidade e abrindo, nesse processo, novos e instigantes tópicos de investigação para os estudos sobre a comunicação nas organizações. Em especial, essas iniciativas nos fazem questionar a quem cabe o papel de vigilância sobre a comunicação das organizações, bem como refletir acerca das características singulares que perpassam tal processo de monitoramento quando o mesmo lida com práticas abusivas ambíguas e que buscam influenciar a opinião pública de maneira difusa.

Numa reflexão sobre tal temática, Henriques e Silva (2013) apontam como a imprensa, em seu tradicional papel de watchdog, é permeada por entraves que restringem

'Entre os principais exemplos podemos destacar o PRWatch (www.prwatch.org) e o SpinWatch (www.spinwatch.org) e o SourceWatch (www.sourcewatch.org). 
seu desempenho na função de vigilância da comunicação das organizações, sendo incapaz de, por si, exercer tal papel. O surgimento de iniciativas civis voltadas para o monitoramento de tais práticas denota um reconhecimento similar de certos atores sociais sobre as limitações da imprensa, que buscam fazer com que os públicos tentem se organizar para ocupar o que julgam ser uma importante lacuna na vida contemporânea. Os autores destacam, porém, que a atuação dos públicos não se encontra livre de constrangimentos, havendo diversas barreiras e desafios que impõem limites aos esforços civis, apontando ainda que de forma mais generalizada para alguns destes.

O presente artigo tem como objetivo aprofundar a discussão sobre a vigilância civil, focando especialmente nos desafios enfrentados para monitorar as práticas de comunicação abusivas empregadas pelas organizações. Para tanto, se torna fundamental deslocar a atenção para um aspecto ainda pouco explorado da temática, porém de implicações fundamentais para o embasamento de investigações futuras: o que, afinal, configura uma prática de comunicação abusiva? Nesse sentido, acreditamos na importância de empreender uma exploração mais extensiva sobre essas práticas com o intuito de compreender as limitações dos processos de vigilância que a sociedade civil pode promover sobre elas.

Tal esforço reflexivo acerca dessas práticas perpassa a construção de uma melhor compreensão sobre como elas diferem dos chamados crimes corporativos, principalmente por visarem corromper a opinião e a boa fé públicas. Configuram, assim, uma categoria distinta de atividade, sendo dotadas de uma complexidade e de um aspecto difuso que nos permitem vislumbrar facetas da própria vulnerabilidade dos públicos. Evidentemente, tal categoria é conformada por uma enorme multiplicidade de práticas, cada qual com características e dinâmicas que impõem limitações variadas a serem enfrentadas no exercício de monitoramento das mesmas.

Frente a tal cenário, optamos por focar um tipo de prática específica na tentativa de captar como suas lógicas operam de forma a estabelecer desafios para aqueles que buscam exercer a vigilância sobre a mesma. Concentramos, assim, nossos esforços em esmiuçar o astroturfing, entendido como uma prática que consiste na criação de uma manifestação de um público simulado - para tanto, traçamos um breve histórico sobre o mesmo e sua utilização por organizações como uma estratégia para influenciar a opinião pública para, em seguida, empreendemos uma exploração mais aprofundada sobre os pormenores e dinâmicas que caracterizam o astroturfing, embasando-nos em resultados de um estudo de caso sobre a campanha "Eu sou da Lapa", ocorrida no Rio de Janeiro em 2005. Destacamos, especialmente, a forma com que tais dinâmicas configuram uma prática, em sua essência, aberta, dúbia e indeterminada, o que torna ainda mais complicado apontar para seus limites exatos e impõe constrangimentos diversos para aqueles que buscam monitorar a mesma.

\section{CRIMES CORPORATIVOS E A TENTATIVA DE CORROMPER A OPINIÃo PÚBLICA}

Os chamados crimes corporativos não são uma categoria definida com precisão. Por um viés mais estreito, tal alcunha designa a infringência de dispositivos legais que 
variam em cada lugar, abarcando ações ou omissões de empresas e corporações que são tipificadas como crime. Eles são também reconhecidos, por vezes, como "crimes do colarinho branco", expressão criada pelo sociólogo Edwin Sutherland em 1939. A alcunha crime corporativo, porém, é muitas vezes ainda mais abrangente, cingindo casos de monopólio, descarga de poluentes tóxicos acima dos limites estabelecidos, negligência sistemática de condições de segurança, utilização de trabalho infantil, suborno, fraudes e outros (Mokhiber, 1995).

Podemos observar que o comportamento das empresas pode ser considerado criminoso não só por seus atos, mas também por negligência e omissão nos casos em que deveria assumir alguma responsabilidade. Do primeiro caso são exemplos fraudes e atos de corrupção ativa ou passiva no relacionamento com poder público e agências governamentais. Tais ações, pelo seu potencial de afetação, constituem algo importante na dimensão pública. Do segundo são notórios os casos de prejuízos causados por sua operação ou por acidentes operacionais - tanto os que causam danos difusos (ao meio ambiente em geral) como específicos a um conjunto de pessoas em particular, mas que alcançam uma importância coletiva. Tais situações se encaixam numa rubrica genérica de crime corporativo também pelo caráter publicamente reprovável, o que, para além de seus aspectos essencialmente legais e jurídicos, vincula essas ações a um juízo pela opinião pública.

Aqui encontramos um ponto crucial: em princípio, os atos das organizações passam por um duplo escrutínio, um duplo juízo que com frequência instaura uma tensão e um momento crítico nas relações com a opinião pública. É certo que se espera das organizações o cumprimento das leis, e o fato de vir à tona alguma infração pode custar-lhe danos à sua imagem e queda em sua reputação. Isso só acontece, no entanto, se o fato é de conhecimento público - e, mesmo assim, depende de uma escala que transcenda círculos de públicos específicos e alcance a opinião pública. Tanto a imprensa, investida da função de watchdog, quanto os públicos que instituem mecanismos de vigilância civil sobre as organizações, possuem aí um papel essencial, capaz de amplificar a formação de um juízo público, cobrar a responsabilidade e pressionar as autoridades para desencadear os efeitos legais.

Além dos crimes corporativos, há outra categoria de atos a ser considerada. Dentre os muitos tipos de fraude que podem ser praticadas por organizações encontram-se também aquelas que corrompem a boa fé dos públicos e são praticadas diretamente contra a opinião pública. Em sua versão mais simples pode-se enquadrar aí a prática da chamada publicidade enganosa ou abusiva (muitas vezes alcançada pela tipificação legal, como no Código de Proteção e Defesa do Consumidor brasileiro). Mas há também outras práticas nem sempre fáceis de enquadrar, dado seu caráter sub-reptício, e que podem ser ética e moralmente questionadas.

Nessa categoria podemos identificar um conjunto bastante variado de práticas que visam influenciar a opinião pública e abarcam, entre outras, a distorção de informações sobre interesses privados, a tentativa de plantar notícias falaciosas, a criação de falsos acontecimentos, o ato de espalhar boatos ou rumores, a simulação de públicos ou de 
situações que podem influenciar os públicos, a criação de organizações de fachada para disseminar informações ou defender determinados pontos de vista como uma terceira parte desinteressada ou a ação de recrutar cientistas para que esses, sem divulgar seus vínculos com as organizações, tentem influenciar o debate sobre controvérsias públicas aparentando neutralidade.

Algumas dessas práticas costumam ser reconhecidas como golpes de propaganda ou golpes de marketing, pensadas como meras astúcias usadas na relação com os públicos e com a opinião pública. Outras, porém, tornaram-se objeto de reflexões mais sistemáticas nas últimas décadas, devido principalmente a um crescente reconhecimento de sua capacidade de corromper a opinião pública. Algumas ganharam inclusive denominações próprias que ajudam a construir um histórico sobre a sua utilização e refletir sobre suas lógicas, dinâmicas e efeitos. É o caso, por exemplo, do astroturfing - termo que designa as manifestações de públicos simulados.

Importante notar que, apesar de terem emergido com contornos mais definidos na esfera pública apenas nas últimas duas décadas, a origem de grande parte dessas práticas remete a um período anterior, figurando em textos clássicos sobre a propaganda na primeira metade do século XX. Elas marcam presença, por exemplo, no trabalho e na atuação de Edward Bernays (2005; 2011), um dos maiores propagandistas norte-americanos do século passado; nos estudos realizados pelo Institute for Propaganda Analysis (IPA), associação formada por pesquisadores com o objetivo de examinar a utilização da propaganda nos EUA entre 1937 e 1942; e nas reflexões sobre a propaganda do psicólogo Leonard Doob (1935).

A vinculação dessas práticas com a propaganda permite inferir um ponto fundamental sobre as mesmas: como todas as práticas persuasivas de propaganda, os exemplos que citamos anteriormente desafiam os limites das relações de influência, mas nem sempre são fáceis de tipificar e comprovar como uma fraude, dado, principalmente, seu caráter dissimulado. Em seu âmago, elas constituem um jogo complexo de informações e contra-informações, atuam ocultadas pela barreira do segredo e são calcadas em ambiguidades capazes de construir cenários que oscilam entre aspectos reais e falsos, criando trilhas difíceis de serem seguidas e tornando progressivamente mais árdua a função de denunciá-las. São práticas com efeitos incertos e difusos, não sendo fácil apontar para os mesmos ou mensurar suas consequências diretas. Os limites éticos e morais são, em geral, nebulosos, sendo um desafio pensar qual o ponto em que elas cruzam o limiar do eticamente aceitável.

Enquanto os crimes corporativos ganharam destaque nas últimas décadas, tornando-se cada vez mais consolidados em vários ordenamentos jurídicos, as práticas que corrompem a opinião pública permaneceram, em grande parte, à margem das legislações. Podemos pensar que o próprio caráter difuso dessas práticas propicia o surgimento de um cenário análogo ao que Sutherland vislumbrava em 1949 para os crimes corporativos, no qual esses atraiam pouca atenção pública e do sistema jurídico por gerarem apenas um "ressentimento relativamente desorganizado do público" (Sutherland, 1949) - e foram necessárias várias décadas de um amplo esforço de teóricos, juristas e da 
própria sociedade civil para que essa barreira fosse superada e os crimes corporativos adquirissem o reconhecimento amplo atual. No que tange às práticas de comunicação que corrompem a opinião pública, é válido pensar que a própria insuficiência histórica na vigilância sobre as mesmas contribuiu para que elas não tenham o mesmo reconhecimento social. Como notado anteriormente por Henriques \& Silva (2013), a imprensa em sua função característica de watchdog é permeada por entraves que dificultam sua atuação na função específica de vigilância sobre essas práticas - dificuldades impostas tanto pela natureza sistêmica complexa dos media como também por uma interação bastante complexa com as práticas que ela deveria monitorar.

Dessa forma, as práticas de comunicação abusivas das organizações, que corrompem a opinião pública, acabavam escapando também ao duplo escrutínio que identificamos anteriormente - não regulamentadas por leis e sem conseguir penetrar em espaços de visibilidade ampliada, permaneceram durante muito tempo longe dos olhares e julgamentos da opinião pública. É importante notar, porém, que o surgimento de iniciativas de vigilância civil voltados para o monitoramento dessas práticas deu início a um movimento que está reconfigurando esse cenário. Essa rede de vigilância, impulsionada por possibilidades trazidas pela internet no que tange a uma configuração diferenciada da opinião pública e da atuação coletiva, tenta agir de maneira a jogar luzes sobre tais condutas das organizações e fazer com que elas assumam a responsabilidade por suas ações, dando origem a um grande número de denúncias envolvendo algumas das maiores empresas do mundo.

Os públicos organizados, contudo, devem também enfrentar inúmeras limitações para ocupar esse papel de vigilância. Eles precisam lidar com o imperativo da construção de uma credibilidade para que suas denúncias reverberem na esfera pública, superar a barreira do segredo, algo que muitas vezes requer conhecimentos especializados, e conquistar uma visibilidade ampla, atingida principalmente por meio da mídia, para que suas atividades tenham impacto social (Henriques \& Silva, 2013). Além disso, devem encarar também desafios oriundos das próprias características e dinâmicas daquelas estratégias de comunicação calcadas na ambiguidade. Cada uma das práticas abusivas que citamos anteriormente apresentam lógicas particulares de grande complexidade que devem ser encaradas para que as mesmas possam ser monitoradas e que precisam ser abordadas para uma maior compreensão sobre a vigilância civil. Nas próximas sessões, abordamos especificamente o astroturfing, observando como características de sua dinâmica configuram entraves significativos para o monitoramento.

\section{ASTROTURFING: ORIGENS E EVOLUÇÃo DA PRÁTICA}

O termo astroturfing teve sua origem em 1985. Naquele ano, o senador Lloyd Bentsen, um democrata do Texas envolvido em um acirrado debate sobre aumentos em benefícios dos seguros de vida, recebeu em seu escritório centenas de cartas que defendiam um posicionamento similar ao das seguradoras americanas, cartas essas semelhantes em seu conteúdo, porém assinadas por diferentes cidadãos que se diziam preocupados com a situação - algo que causou desconfiança no político. 
Tais suspeitas levaram o senador a comentar que "uma pessoa do Texas sabe dizer a diferença entre grassroots e AstroTurf... isso é correspondência criada" (Russakoff \& Swardon, 1985, tradução nossa). Em tal comparação, dois termos eram contrapostos: grassroots (ou "raízes de grama"), nome pelo qual são conhecidas as manifestações populares espontâneas nos EUA, e o AstroTurf, marca de grama artificial criada pela Monsanto na década de 1960 e famosa pela sua similaridade com a aparência da grama real. Afirmava, então, que tais cartas não eram espontâneas, mas sim uma tentativa de aparentar um apoio popular para a causa das seguradoras.

Nas quase três décadas desde o surgimento do termo astroturfing para designar manifestações de públicos simulados, um fator fundamental para o aumento do reconhecimento e da repercussão sobre o assunto é a ligação da prática com a indústria de relações públicas e algumas das maiores organizações do mundo. Tal ponto é explorado por uma série de denúncias sobre como algumas das mais renomadas agências de RP empregam o astroturfing em campanhas em favor de grandes corporações e de governos (Stauber \& Rampton, 1995; Hoggan, 2009) - denúncias que vieram na esteira do movimento mais amplo de crítica e vigilância sobre as práticas de comunicação abusivas realizadas por organizações privadas que exploramos anteriormente.

Um dos primeiros casos de astroturfing envolvendo uma organização privada com grande repercussão mundial ocorreu em 1993. Foi nesse ano que a Philip Morris (atualmente Altria), uma das maiores empresas americanas do setor de cigarros, financiou a criação da National Smokers Alliance (NSA), desenvolvida pela agência de RP Burson-Marsteller2. A NSA se apresentava como uma associação grassroots, criada por fumantes com o objetivo de lutar pelo direito de fumar, algo que estaria em risco devido às novas legislações que limitavam o consumo do cigarro. A associação, porém, não era realmente espontânea e nem ao menos contava com membros na época da sua fundação, sendo uma tática financiada pela Phillip Morris para exercer pressão no sentido de barrar tais legislações (Hoggan, 2009).

Nas últimas duas décadas, as principais agências de RP do mundo foram alvo de denúncias sobre a utilização do astroturfing em ações para organizações diversas, entre elas a Edelman³, acusada de desenvolver uma campanha para o WalMart utilizando de tais práticas (Barbaro, 2006); a APCO4, também envolvida na criação de falsos grupos de suporte para a Phillip Morris e a indústria do tabaco (Hoggan, 2009); a Ruder Finn5, que controlaria grupos financiados por empresas para atacar o tratado de Kyoto e a ideia do aquecimento global (Hammond, 1997); e a própria Burson-Marsteller, envolvida não apenas em denúncias de utilização do astroturfing para a indústria do tabaco, como também para a indústria de energia (Beder, 1998). As constantes acusações e denúncias

\footnotetext{
${ }^{2}$ A Burson-Marsteller é parte da WPP, maior conglomerado de comunicação do mundo em 2013. Informações disponíveis em www.wpp.com/wpp/about [acesso em 27 de julho de 2014].

${ }^{3}$ Segundo dados do O'Dwyer Ranking de 2012, a maior agência de RP do mundo. Lista disponível em www.odwyerpr.com/ pr_firm_rankings/independents.htm [acesso em 27 de julho de 2014].

${ }^{4}$ Segunda maior agência de RP do mundo (O'Dwyer Ranking, 2012).

${ }^{5}$ Quarta maior agência de RP do mundo (O'Dwyer Ranking, 2012).
} 
ressoaram também nas associações profissionais de RP, com a Public Relations Society of America (PRSA) e a Chartered Institute of Public Relations (CIPR), principais instituições da área nos Estados Unidos e no Reino Unido respectivamente, passando a mencionar de forma nominal o astroturfing em seus códigos de ética como uma prática que não deveria ser realizada pelos seus membros.

O elevado número de casos nos quais a indústria de RP emprega o astroturfing chama a atenção inclusive dos próprios praticantes da área, gerando críticos que, de posse de conhecimentos especializados, passam a também denunciar abusos e deslizes éticos - se juntando à rede de vigilância civil sobre o tema. Um desses é o canadense James Hoggan, presidente da agência Hoggan and Associates. Em sua obra 'Climate Cover-up' (2009), sobre os elos de organizações da indústria de energia com grupos que negam a existência do aquecimento global, Hoggan analisa uma série de casos de astroturfing praticados por agências de RP, afirmando que vivemos, mesmo sem consciência disso, na "Era do Astroturfing".

O astroturfing ganhou destaque também com o advento e a popularização da chamada web 2.0, que traz entre suas características um aumento sem precedentes de publicização de opiniões - o que, somado ao anonimato da internet, resulta em possibilidades inéditas para o astroturfing. O jornalista britânico George Monbiot, um dos principais autores a trabalhar com denúncias sobre o assunto, aponta que a internet cria "uma oportunidade de ouro para empresas e governos praticarem o astroturfing: falsas campanhas grassroots, que criam a impressão que um grande número de pessoas está demandando ou opondo determinadas medidas" (Monbiot, 2011, tradução nossa).

Segundo Monbiot, existe um acumulo cada vez maior de evidências, nos mais diversos países do mundo, sobre como os fóruns e sessões de comentários na internet estão sendo ocupados por pessoas que não são quem elas dizem serem - evidências essas materializadas na forma de denúncias registradas sobre a prática no Reino Unido (Monbiot, 2011), na Suécia (Royal, 2010), na Espanha (Jessen \& Kesser, 2012), na China (Mackinnon, 2010), entre outras. Recentemente, a própria União Europeia foi acusada de empregar práticas que remontam ao astroturfing para simular um apoio da sociedade civil para suas atividades (Snowdon, 2013).

Apesar do crescente reconhecimento mundial, o astroturfing permanece relativamente incógnito no Brasil, com poucos casos ganhando espaço no cenário público. Um dos primeiros registros no país foi o episódio do "Eu sou da Lapa", ocorrido no Rio de Janeiro, em 2005, e que consistia em um suposto movimento popular para revalorização daquele bairro carioca. Ele foi criado, entretanto, por uma agência de publicidade contratada por uma construtora que estava em vias de lançar um empreendimento imobiliário no bairro. Tal ação objetivava simular uma manifestação a favor da Lapa como uma forma de aumentar a busca pelos imóveis da construtora - para tanto, personalidades locais foram contratadas para serem porta-vozes do suposto movimento, um site e uma comunidade no Orkut do "Eu sou da Lapa" foram criados e uma série de materiais e brindes distribuídos na cidade, como camisetas, guias da Lapa, adesivos e outros. Durante todo o mês de outubro daquele ano, o "Eu sou da Lapa" tomou as ruas do Rio de 
Janeiro dizendo ser um movimento da própria sociedade civil, que contava com apoios diversos e que estava se espalhando pela cidade.

Terminada a ação, a agência responsável pelo caso o inscreveu no Prêmio Aberje, a maior premiação da área de comunicação empresarial do Brasil, realizado pela Associação Brasileira de Comunicação Empresarial. Ao descrever as estratégias empregadas, a agência afirmou ter criado "um movimento popular, usando a ferramenta de astroturfing (ações publicitárias que parecem iniciativas espontâneas)" ${ }^{6}$, revelando, assim, a natureza artificial da ação. Tal revelação, porém, não gerou uma repercussão negativa ou ganhou espaço na mídia, o que evidencia um desconhecimento sobre a prática no país - ao contrário, o caso foi finalista da etapa regional do Prêmio Aberje. Apenas recentemente denúncias sobre a utilização do astroturfing no campo político foram tratadas por veículos importantes de comunicação, principalmente devido a uma controvérsia envolvendo a Revista Veja e o Partido dos Trabalhadores no episódio do tuitaço \#VejaBandida7, mas a temática ainda permanece sem uma grande repercussão no Brasil.

Podemos observar, de maneira geral, que as últimas décadas marcaram o surgimento do astroturfing na esfera pública, resultando em um crescente número de denúncias sobre a utilização da prática em diversos países. São pouquíssimos os casos, porém, que resultaram em sanções para os envolvidos, e acreditamos que tal fato pode estar relacionado com um elemento fundamental da prática que dificulta o processo de denúncia e apuração da mesma: a ambiguidade inerente ao astroturfing.

\section{UMA PRÁTICA ESSENCIALMENTE AMBÍGUA}

Na presente sessão exploramos algumas evidências importantes que corroboram a reflexão anterior sobre as limitações à vigilância civil relacionada ao astroturfing. Para tanto, apresentamos achados frutos de uma pesquisa realizada acerca da campanha "Eu sou da Lapa", caso ocorrido no final de 2005 na cidade do Rio de Janeiro. Tal pesquisa teve como escopo realizar não uma denúncia sobre um caso de astroturfing, mas sim empreender uma investigação acerca das dinâmicas existentes na prática, o que justificou a opção de trabalhar apenas com informações publicamente disponíveis sobre o episódio. A campanha "Eu sou da Lapa" foi escolhida, nesse sentido, pela pluralidade de materiais públicos sobre a mesma, incluindo, entre outros, um website do movimento, uma comunidade na rede social Orkut, um manifesto do movimento que foi amplamente distribuído, uma apresentação sobre o caso realizada pela agência responsável pela ação e disponibilizada na internet, bem como dezenas de matérias na imprensa que abordaram o movimento durante os meses de outubro, novembro e dezembro de 2005.

Tal pluralidade possibilitou um recorte empírico amplo, com o material recolhido sendo classificado em três categorias que permitiram vislumbrar elementos da lógica

\footnotetext{
${ }^{6}$ Afirmação encontrada no arquivo de casos da agência, disponível em http://www.blogdeguerrilha.com.br/cases [acesso em 27 de julho de 2014].

${ }_{7}$ Segundo a matéria "Falcão e os insetos", publicada em 16 de maio de 2012 pela Revista Veja, o \#VejaBandida, que ocupou o segundo lugar nos assuntos mais falados do Twitter no dia 18 de abril de 2012, era um astroturfing, com mais de $50 \%$ das mensagens originadas de um número pequeno de perfis que incluíam robôs e scripts (Veja, 2012).
} 
que perpassa aquela prática: a) proferimentos, composta pelos materiais oriundos da própria agência responsável pelo caso e que trazem afirmações sobre a natureza e as características do movimento "Eu sou da Lapa", ou seja, aqueles a partir dos quais ela tenta definir publicamente o que é aquela manifestação; b) ações realizadas pelo movimento, identificadas a partir do material coletado sobre o caso "Eu sou da Lapa"; e c) reverberações, relacionadas com os comentários sociais sobre o caso, ou seja, a reverberação sobre ele na imprensa e nas mídias sociais, sendo que no total foram trabalhadas 25 matérias de jornais e 278 postagens em redes sociais. Por meio desse recorte empírico, foi possível analisar algumas das dinâmicas do astroturfing, evidenciando como a prática é perpassada por ambiguidades que conferem a ela um caráter aberto e pouco definido que estabelece entraves para o seu monitoramento, e apresentamos a seguir três observações nesse sentido.

Uma primeira observação é de que a prática se apresenta mais complexa do que simples mentiras, conjugando aspectos reais e enganosos. Durante o episódio do "Eu sou da Lapa", diversas ações efetivamente ocorreram: personalidades locais vestiam a camiseta do movimento e realizavam manifestações, incluindo apresentações musicais e uma escultura de areia dos Arcos da Lapa, um dos principais símbolos do bairro, em Copacabana; bares da Lapa ostentavam kits do movimento, como guardanapos e outros itens personalizados pelo "Eu sou da Lapa"; brindes em nome do movimento eram levantados em diversos estabelecimentos da cidade, seguidos por rodadas de chope gratuitas distribuídas para os presentes; bancas de revistas distribuíam gratuitamente guias culturais da Lapa assinados pelo movimento, assim como adesivos e broches do mesmo; o site "Eu sou da Lapa" foi colocado no ar, trazendo inclusive o manifesto do movimento, e "bandeirões" do "Eu sou da Lapa" eram exibiam nos estádios. Além dessas ações de promoção, havia pessoas comuns que de boa fé se manifestavam, por identificar-se com o bairro e com a proposta.

Aquele caso não era, assim, algo que pode ser encarado como uma falsa notícia ou uma mentira facilmente refutável - as pessoas encontravam, durante seu cotidiano, várias ocorrências concretas do movimento. Por outro lado, essas ações traziam elementos bastante ambíguos, principalmente no que tange às falsas interpretações sobre as mesmas por parte da agência responsável pelo caso. Elas não eram, nesse sentido, exatamente o que a agência alegava, já que essa as divulgava como sendo de um movimento social, oriundas de públicos que estariam manifestando seu apoio ao mesmo. $O$ elemento de simulação, evidentemente, não aparece nos proferimentos do movimento, revelando, assim, um aspecto de ocultamento e de enganação, uma tentativa de fazer com que os sujeitos acreditassem em algo que não estaria acontecendo exatamente daquela forma.

Um segundo elemento que emerge da análise do caso "Eu sou da Lapa" que ajuda a explorar as limitações ao monitoramento do astroturfing é a criação de uma trama complexa que se dá no decorrer dessa prática. Podemos encarar o astroturfing como um exemplo do que Daniel Boorstin (1962) chama de pseudo-acontecimento: um acontecimento construído estrategicamente para se passar por verdadeiro - com o prefixo 
"pseudo" sendo empregado pelo autor para ressaltar justamente o aspecto enganoso presente nos mesmos. O astroturfing, sob esse viés, consiste em uma manifestação de um público que não existe, sendo, no entanto, um construto orientado para fazer com que as pessoas acreditem que um público estaria de fato se movimentando.

Ao explorar a temática, Boorstin sustenta que uma das características definidoras do fenômeno consiste na construção de uma trama a partir do pseudo-acontecimento "original", o que o tornaria cada vez mais naturalizado e menos reconhecível. Essa trama se desenvolve por meio das impressões de jornalistas e das conversações ordinárias sobre o fato, das interpretações sobre o ocorrido por parte de um especialista, de especulações sobre as causas ou sobre as consequências do mesmo - ou, em outras palavras, através da reverberação daquele acontecimento.

É fundamental entender tal reverberação não apenas como um conjunto de reações imediatas àquele acontecimento, mas sim como uma trama complexa formada por uma multiplicidade de elementos. Ela é composta a partir das reações da mídia e dos públicos sobre o que acontece, mas também é tecida por novos eventos que se desdobram a partir do pseudo-acontecimento original, e que são também acompanhadas pelas suas respectivas reverberações - são novos acontecimentos interpostos que vão reelaborando sentidos, alguns desses podendo, inclusive, configurar novos pseudo-acontecimentos, planejados e programados justamente para auxiliar na construção dessa trama.

Quanto mais essa trama se constrói, ou seja, quanto mais o pseudo-acontecimento reverbera na sociedade e é apropriado por ela, mais a sua natureza artificial é eclipsada pela complexidade da situação. Algo semelhante foi percebido por pesquisadores da Indiana University, nos Estados Unidos, ao explorar tentativas de astroturfing no período eleitoral norte americano. Segundo o grupo, uma vez que essas tentativas efetivamente caem na corrente de conversações ordinárias, sua natureza simulada se torna rapidamente indistinguível (Ratkiewicz et al., 2011).

Durante a análise do "Eu sou da Lapa" foi possível captar lampejos desse processo, observando como um emaranhado de desdobramentos, novas intervenções estratégicas e interações sociais sobre aquela situação construíam progressivamente uma trama. As ações realizadas pela agência criadora do caso, por exemplo, ocorriam sucessivamente, fazendo com que o movimento parecesse algo orgânico. Elas fomentavam também uma impressão de que muitos já estavam mobilizados ao redor daquela causa, de que aquelas manifestações contavam com a participação de um vasto número de pessoas e era um assunto comentado amplamente, sobre o qual todos emitiam ou estavam em vias de emitir opiniões e apoios.

O episódio conquistou também visibilidade midiática. Ao todo, encontramos vinte e cinco aparições daquele movimento na mídia entre outubro e novembro de 2005 , incluindo em veículos nacionais - por exemplo, a participação de um saxofonista , uma das personalidades locais recrutadas pela agência, no Programa do Jô da Rede Globo com um broche do movimento. Explorar a comunidade "Eu sou da Lapa" no Orkut nos permitiu vislumbrar também como algumas das ações geravam comentários diversos 
dos usuários, principalmente as rodadas de chope oferecidas gratuitamente nos bares da cidade - alguns contando sua experiência, outros lamentando terem perdido a oportunidade de ganharem a bebida e projetando onde seriam as próximas intervenções.

Temos assim pequenas interações ao redor daquele movimento que desenvolvem um emaranhado cada vez mais denso. Sucessivamente, aquele pseudo-acontecimento se tornou algo de certa forma naturalizado e consolidado. Observamos, nesse sentido, como o "Eu sou da Lapa" foi assim tratado pela imprensa ao final da campanha, sendo prontamente incorporado em matérias como um elemento consolidado de um quadro de sentidos sobre a revitalização do bairro, cenário que torna mais ambíguo lidar com aquele caso.

O terceiro elemento que torna o astroturfing ainda mais ambíguo e de difícil monitoramento é a possibilidade de mobilização de públicos. A principal peculiaridade do astroturfing reside justamente na possibilidade de formação do público que antes era simulado. Diferentemente de, por exemplo, um vazamento de uma substância tóxica em uma fábrica, que afetaria diversos indivíduos ao redor do acontecimento e daria origem a públicos que se movimentariam em relação ao fato, a essência do astroturfing está na existência de um público que já é apresentado, mesmo que de maneira simulada.

Uma dimensão que constantemente ganha destaque no astroturfing está relacionada com um chamado à mobilização que busca fazer com que os sujeitos passem a agir frente àquele acontecimento. Trata-se, porém, de um apelo específico à mobilização, que busca fazer com que os sujeitos se juntem ao público simulado (que lhes parece autêntico) que está se manifestando, de forma a ocultar o caráter enganoso do mesmo, tornando-o mais verossímil. A National Smokers Alliance, que citamos anteriormente, é um caso emblemático sob esse aspecto, tendo sido criada para passar a impressão de ser uma manifestação espontânea de cidadãos preocupados com as ameaças ao direito de fumar. Assim que criada, porém, a NSA coloca em ação uma "elaborada campanha que usava anúncios de página inteira em revistas, telemarketing direto, agentes contratados, números 0800 e boletins informativos" (Stauber \& Rampton, 1995: 29, tradução nossa) para recrutar pessoas para a associação. A NSA atuava, portanto, em duas frentes: uma delas manifestava um público que, a princípio, era simulado, enquanto a outra empreendia um esforço para trazer alguma autenticidade para aquele público, fazer com que pessoas de fato se mobilizassem por aquela causa.

Assim como um pseudo-acontecimento necessita da interação social sobre ele ou seja, do desenvolvimento de uma trama - para que os elementos artificiais de sua construção sejam eclipsados, o astroturfing depende da formação de um público mais autêntico para que possa, com maior efeito, influenciar a opinião pública. Frente a uma multiplicidade de sujeitos defendendo aquelas ideias, atuando como aquele público, se torna praticamente impossível determinar qual é o seu ponto original, localizar sua natureza artificial.

Podemos observar em tal formação algo de planejado, já que a própria manifestação daquele público simulado traz em si a configuração básica do que será o público mobilizado - apresenta um modo de ver coletivo da situação que baliza as próprias ações que estão sendo desenvolvidas. Ela pré-figura e projeta um público, convocando 
os sujeitos a se juntar a ele e posicionarem-se alinhados dentro das possibilidades oferecidas por aquela situação, atuando assim de forma a desvelar ações possíveis naquele momento sobre uma determinada causa - no caso do "Eu sou da Lapa", esse posicionamento se relacionava com o ato de vestir a camiseta daquele movimento, utilizar algum material que estampava aquele nome. A página principal do site "Eu sou da Lapa" relacionava a utilização de materiais do movimento como uma maneira de aderir ao mesmo ("peça já o seu e faça parte desse movimento"), sendo possível observar, principalmente por meio da comunidade do "Eu sou da Lapa" no Orkut, como as pessoas agiram de tal forma, solicitando camisetas e adesivos.

Dessa forma, podemos encarar o astroturfing como uma "centelha", algo que pode dar início a um processo de mobilização de públicos. A prática oferece um posicionamento básico para os sujeitos agirem como parte daquele público que já estaria se manifestando. Ao mesmo tempo, traz apelos que incentivam os sujeitos a assumirem tal posição dentro de um quadro de sentidos, ou seja, a agir. Tais fatores incluem uma ação simples, que não demanda muito dos sujeitos (vestir uma camiseta apoiando um movimento de revitalização de um bairro tão emblemático como a Lapa é um exemplo) e a própria ideia de que um coletivo já está mobilizado ao redor daquele movimento, ou seja, a noção de que muitos outros sujeitos já estão se manifestando, espontaneamente, daquela forma.

Apesar de ser um elemento fundamental na dinâmica do astroturfing, é evidente que nem todos os casos da prática conseguem fazer com que haja tal mobilização de públicos. Quando há sucesso em tal formação, porém, se torna complicado distinguir o fenômeno, isolar e entender o que é enganoso e o que é autêntico naquele público quando mais pessoas são mobilizadas, mais elementos de autenticidade são agregados naquele público simulado. Quando todos os bares da Lapa começam a distribuir os materiais daquele movimento, quando uma pluralidade de pessoas começa a vestir aquela camiseta, utilizar os seus broches e afirmar que eles também são da Lapa, como apontar para o público que era simulado? E ainda mais relevante: como caracterizar a prática como abusiva e denunciá-la?

\section{Considerações Finais}

Ao final de nosso percurso, nos parece importante retomar a questão dos crimes corporativos e das práticas abusivas de comunicação que tentam corromper a opinião pública. Os crimes corporativos, assim como qualquer crime, só são punidos através de sua reconstituição discursiva, que permite expor os fatos em sua materialidade a julgamento, como história coerente e comprovável. As características imateriais e difusas das fraudes contra a opinião pública engendradas pela propaganda e por muitas organizações desafiam essa noção, já que eles próprios estão dentro da lógica discursiva fluida das narrativas em disputa. No entanto, podem não escapar a uma punição pela desmoralização e possível erosão da confiança, ou seja, pelo juízo da opinião pública. O problema passa a ser como capturar essas práticas que tentam iludir a boa fé dos públicos. 
Como observamos, essas são práticas difíceis de serem apreendidas, dotadas de aspectos que geram constrangimentos e desafios para os públicos que tentam ocupar uma posição de monitoramento. Nossa intenção no presente artigo não era traçar um quadro extensivo dessas dificuldades, algo que demandaria análises diversas devido à multiplicidade de práticas que buscam corromper a opinião pública, mas sim explorar uma dessas práticas para demonstrar sua complexidade. O astroturfing, observado como prática ambígua, complexa e indeterminada, expõe algumas das vulnerabilidades dos públicos e das limitações dos processos de vigilância pela sociedade civil, fornecendo novos subsídios para investigações futuras sobre tal temática.

Assim, é importante observar que muitas das denúncias sobre o astroturfing se voltam apenas para os aspectos enganosos que entram em jogo, não reconhecendo que nela coexistem também manifestações espontâneas e autênticas que tornam ainda mais complicado fazer sentido sobre tal prática - o que pode, inclusive, diminuir a força de tais denúncias perante os públicos, na medida em que eles perceberem que aspectos reais foram deixados de lado. A construção de uma trama, a partir da interação social, ao redor de pseudo-acontecimentos é outro ponto sensível, pois relega o caráter enganoso desses "acontecimentos fabricados" a um segundo plano, gerando um sentimento de frustração em quem tenta desmascará-lo e tornando progressivamente mais complicado apontar para os limites exatos da existência da prática.

Finalmente, quando o astroturfing consegue fazer com que os sujeitos se mobilizem e passem a atuar de forma semelhante ao público inicialmente simulado acaba por instituir um enorme desafio para aqueles que buscam monitorar a prática. Nesse momento, o limiar entre o simulado e o autêntico se torna mais confuso, e a denúncia sobre o caráter enganoso e artificial da prática pode acabar sendo um fator que aumenta a mobilização daqueles que estão genuinamente engajados e manifestando sua opinião alheios à simulação inicial, algo que aconteceu no caso da \#VejaBandida - após a denúncia da Revista Veja de que aquele episódio seria um astroturfing, um novo tuitaço, dessa vez com o marcador \#VejaTemMedo, foi realizado por aqueles que participaram do original, tendo como principal mensagem uma crítica à denúncia da Veja, afirmando que a mesma se tratava de uma tentativa de deslegitimar a opinião expressa pelos cidadãos.

O astroturfing se revela, assim, uma prática particularmente ambígua e de difícil monitoramento. Mesmo quando as redes de vigilância conseguem captar casos da utilização de tal estratégia, as lógicas inerentes à mesma fazem com que o processo de denúncia não seja tão simples como apontar uma mentira trivial, o que explica o insucesso de muitas denúncias em gerar constrangimentos públicos a quem emprega o astroturfing.

É importante notar que, apesar das dificuldades enfrentadas, a atuação dessa rede de vigilância civil não é infrutífera, obtendo decisivo sucesso em ampliar a exposição sobre a prática. Como consequência do aumento na repercussão, diversos países começaram a discutir, mesmo que de forma tímida, os aspectos legais envolvidos na questão, mas ainda sem originar uma jurisprudência reconhecível sobre o assunto. Fazendo 
referência à nossa discussão sobre os crimes corporativos, podemos especular que essa atuação marca o fortalecimento de um processo que visa quebrar a barreira erguida por um "ressentimento relativamente desorganizado do público", algo de grande importância para o reconhecimento social sobre essas práticas.

Nesse sentido, dois importantes precedentes foram recentemente estabelecidos em relação ao astroturfing: o Promotor-Chefe do Estado de Nova York concluiu uma investigação que multou 19 empresas locais que realizavam ações de astroturfing virtual (Seltzer, 2013), enquanto a justiça de Taiwan multou a Samsung em aproximadamente 350 mil dólares por utilizar práticas de astroturfing em fóruns online daquele país (Fingas, 2013). Evidentemente, esses são ainda passos modestos frente ao grande conjunto de denúncias sobre o astroturfing construído nas últimas duas décadas. Dadas as dificuldades de caracterização dessa prática como abusiva, perspectivas de pesquisas futuras permanecem abertas para ampliar ainda mais a compreensão sobre sua lógica e sobre a vulnerabilidade dos públicos, bem como explorar novas configurações entre as organizações e a sociedade.

\section{REFERÊNCIAS}

Barbaro, M. (2006) "Wal-Mart Enlists Bloggers", The New York Times, disponível em http://www.nytimes. com/2006/03/07/technology/opblog.html?_r=1, access 27/07/2014.

Beder, S. (1998) "Public Relations Role in Manufacturing Artificial Grass Roots Coalitions", Public Relations Quarterly 43, 2.

Bernays, E. (2011) Crystallizing public opinion, New York: Ig Publishing.

Bernays, E. (2005) Propaganda, New York: Ig Publishing.

Boorstin, D. (1962) The image: a guide to pseudo-events in America, New York: Vintage Books.

Doob, L. (1950) “W. Goebbels principles of propaganda”, The public opinion quarterly, 14, 13.

Fingas, J. (2013) "Taiwan fines Samsung for astroturfing internet comments on its smartphones", Engadget, disponível em http://www.engadget.com/2013/10/24/taiwan-fines-samsung-for-astroturfing-internetcomments, access 27/07/2014.

Hammond, K. (1997) Astroturf Trooper: How the polluters' lobby uses phony front groups to attack the Kyoto treaty, disponível em http://www.motherjones.com/politics /1997/12/astroturf-troopers, access 27/07/2014.

Henriques, M \& Silva, D. (2013) Vigilância civil sobre as práticas de comunicação das organizações privadas: Limites da atuação da imprensa e os desafios do monitoramento pelos públicos, XII Encontro Anual Compós. Salvador.

Hoggan, J. (2009) Climate Cover-Up: The Crusade to Deny Global Warming, Toronto: Greystone Books.

Jensen, M. \& Kesser, B. (2012) Political astroturfing and twitter following in the 2011 spanish campaign, disponível em http://microsites.oii.ox.ac.uk/ipp2012/sites/microsites. oii.ox.ac.uk.ipp2012/files/ astroturf.pdf, access 27/07/2014. 
Mackinnon, R. (2010) "Network authoritarianism in China and beyond: implications for global internet freedom", in Liberation Techonology in Authoritarian Regimes, disponível em http://iis-db.stanford.edu/ evnts/6349/MacKinnon_Libtech.pdf, access 27/07/2014.

Mokhiber, R. (1995) Crimes Corporativos, São Paulo: Página Aberta.

Monbiot, G. (2011) "The need to protect the internet from astroturfing grows even more urgent", The Guardian, disponível em http://www.guardian.co.uk/environment/georgemonbio t/2011/feb/23/needto-protect-internet-from-astroturfing, access 27/07/2014.

Ratkiewicz, J., Conover, M., Meiss, M., Gonçalves, B., Patil, S., Flammini, A. \& Menczer, F. (2011) "Truthy: Mapping the spread of Astroturf in microblog streams", Hyderabad.

Royal, T. (2010) "Samsung's forum astroturfing - not limited to Sweden?", Computer Active, disponível em http://www.computeractive.co.uk/ca/news/1914558/samsungs-forum-astroturfing-limited-sweden, access $27 / 07 / 2014$.

Russakoff, D. \& Swardson, A. (1985) "Tax-overhaul battle follows lawmakers home", The Washington Post, Washington.

Setzer, L. (2013) “Astroturfing dragnet laid by New York State”, ZDnet, disponível em: http://www.zdnet.com/ astroturfing-dragnet-laid-by-new-york-state-7000021101/, access 27/07/2014.

Silva, D. (2013) O astroturfing como processo comunicativo: a manifestação de um público simulado, a mobilização de públicos e as lógicas de influência na opinião pública, Dissertação de Mestrado, Belo Horizonte: Universidade Federal de Minas Gerais.

Snowdown, C. (2013) "Euro puppets: the European Commission's remaking of civil society", in IEA Discussion Paper, 45, disponível em http://www.iea.org.uk/sites/default/files/ publications/files/Euro\%2oPuppets. pdf, access $27 / 07 / 2014$.

Sutherland, E. (1949) The White Collar Criminal, New Haven: Yale University Press.

Stauber, J. \& Rampton, S. (1995) Toxic sludge is good for you: Lies, damn lies and the public relations industry, Monroe: Common Courage Press.

Veja (2012) "Falcão e os insetos", Revista Veja, disponível em http://veja.abril.com.br/noticia/brasil/falcao-eos-insetos-guerrilha-digital-envenena-o-twitter-vejanarede, access 27/07/2014.

$* * *$

Recebido a 30-07-2014

Aceite a 06-10-2014 